\title{
The Pattern of Skin and Venereal Diseases among the Patients Attending OPD of Department of Dermatology and Venereology of Rangpur Medical College Hospital, Rangpur, Bangladesh
}

\author{
Md. Razu Ahmed ${ }^{1 *}$, Md. Khorshed Alam Mondal ${ }^{2}$ \\ ${ }^{1}$ Assistant Professor, Dept. of Dermatology \& Venereology, Rangpur Medical College, Rangpur, Bangladesh \\ ${ }^{2}$ Senior Consultant (Skin \& VD), 250 Bedded Mohammad Ali District Hospital, Bogura, Bangladesh
}

\begin{abstract}
DOI: $10.36348 /$ sjmps.2020.v06i09.004 $\quad$ | Received: 12.09 .2020 | Accepted: 23.09 .2020 | Published: 26.09 .2020
*Corresponding author: Md. Razu Ahmed
\end{abstract}

\section{Abstract}

Background: Skin diseases are very much prevalent in the developing countries. It is generally agreed that pattern of skin \& venereal diseases differ in different countries and within various regions of a country depending upon social, economic, racial \& environmental factor. The morbidity associated with skin and venereal diseases makes them an important public health problem. Very scanty literature is found on the problem which is either disease based, community based or specified population group based. Objective: To assess the pattern of skin and venereal diseases in patients attending OPD of department of Dermatology \& Venereology Of Rangpur Medical College Hospital, Rangpur, Bangladesh. Materials and Methods: It is a descriptive study conducted at Dermatology and Venereology OPD in Rangpur Medical College Hospital, Rangpur, Bangladesh for the period from 1st January, 2019 to 31st December 2019. Six thousand and two hundred and three patients were enrolled during the study period. The study population comprised of newly diagnosed cases as well as relapsing cases presenting in the outpatient irrespective of gender and age. Diagnosis was made on clinical basis. Lab investigations were restricted to the cases where it carried diagnostic importance. Then they were processed with the help of software SPSS (Statistical Package for Social Sciences) version 19.0 and analyzed. Results: Study was conducted on 6203 patients comprising 3373 (54.38\%) males and 2830 (45.62\%) females, who attended skin and VD OPD of Rangpur medical College hospital, Rangpur, Bangladesh during the period of one year. Males were found to be most commonly affected. Male female ratio is 1.2: 1 . Age group between 15 to 29 years carried maximum incidence (43.79\%). All disorders were broadly classified into noninfective (63.5\%), infective (20.2\%) and miscellaneous dermatoses (16.2\%). Eczema 1721 (27.7\%) and fungal infections 694 (11.2\%) came out to be the two top most common cause for OPD attendances. Conclusion: Our study found a higher prevalence of non-infective dermatoses than infective dermatoses. Eczema and fungal infections formed the largest group in their respective categories.

Keywords: Skin diseases; Eczema; Infectious dermatoses; Noninfectious dermatoses.

Copyright @ 2020: This is an open-access article distributed under the terms of the Creative Commons Attribution license which permits unrestricted use, distribution, and reproduction in any medium for non-commercial use (NonCommercial, or CC-BY-NC) provided the original author and source are credited.

\section{INTRODUCTION}

Skin diseases differ in different countries, and within various regions of a country depending on social, economic, racial and environmental factors. Many patients have reported various patterns of skin diseases in different countries. Skin diseases affect all ages from neonate to elderly. It causes harm in a number of ways and can have profound effect on both individual and community. It can lead to significant morbidity due to disfigurement, disability, intractable itch and though rare even death from intractable skin disease. The pattern \& distribution of dermatological diseases differ from one country to another country and in various areas within the same country [1]. Skin diseases can be influenced by so many factors like genetics, environment, race, religion, occupation, nutrition and habit [2]. Geographical factors such as season and climate also contribute to the increased prevalence of certain type skin disorders in a particular area. In developing countries, other than hot and humid climatic condition, low hygiene, poor access to water, overcrowding, high interpersonal contact also play significant etiological role for certain skin diseases like pyoderma, scabies, fungal infection [3]. In developing countries $70 \%$ of the people suffer from skin diseases in some part of their life [4]. Many do not have access to basic skin services and even in developed countries $15 \%$ of the patients apply home remedies before proper medical services [5]. Many of the skin infections are 
endemic in developing countries. However the epidemiology of these diseases is inadequately understood in many areas, particularly in Bangladesh [6]. Different studies have shown different results. However, most of the result from the Indian subcontinent shows similar to the present study result. In developed countries like U.K., Denmark, Egypt, Singapore shows different results. In Indian subcontinent infectious skin diseases are more common than non-infectious diseases even in Ghana [7]. Whereas in Denmark, Egypt and in Singapore dermatoses are more common and in U.K pre malignant and malignant skin diseases are more common [8, 9]. Moreover, there is scarcity of knowledge about common skin diseases which can be very easily treated by general practitioners reducing the burden on specialized centers for management of more complicated skin diseases. In addition there is a need to create awareness among public and primary health care providers to educate people about preventive aspects related to skin diseases so that the burden of disease can be minimized $[10,11]$. Therefore this present study was undertaken to evaluate the pattern of skin diseases among the patients attending the OPD of skin and venereal disease pattern observed in Rangpur medical College hospital, Rangpur, Bangladesh.

\section{Materials \& Methods}

This study was undertaken in the outpatient Department of Dermatology \& Venereology, Rangpur Medical College Hospital, Rangpur, Bangladesh. The study group comprises 6203 patients attending in the outpatient department, Rangpur medical College hospital, Rangpur, Bangladesh, during period of 1st January to 31st December, 2019. All the cases were subjected to thorough history taking including name, age sex, address, religion, economic status of the family along with chief complaints, total duration of disease, related past, family and treatment history, complete general, physical, local and systemic (where necessary) examination. Investigations were done where necessary. All newly diagnosed cases as well as relapsing cases presenting with skin \& venereal diseases, all ages and both sexes, with patient/ guardian giving verbal consent for the study, were included in the study. Burns, congenital/traumatic dermatological problem, acute febrile exanthematic rashes and patients visiting the facility as follow up for the same skin problem were excluded. Data were collected through direct interview of the patients at the respective departments by the researcher and competent colleagues. Collected data was checked and edited first. Then they were processed with the help of software SPSS (Statistical Package for Social Sciences) version 19.0 and analyzed.

\section{RESUlTS}

A total of 6203 (only new patients) patients were included in the study conducted over a period of 1 year, of which $3373(54.38 \%)$ were male and 2830 $(45.62 \%)$ were females. All disorders were broadly classified into noninfective $(63.5 \%)$ (Table-1), infective (20.3\%), and miscellaneous dermatoses (16.2\%) (Table-2). Disease related incidence has been given in (Table 1 \& 2). Most common diseases were found to be eczema $(27.7 \%)$, followed by fungal infections $(11.2 \%)$, erectile dysfunction \& premature ejaculation (6.2\%), acne (5.98\%), seborrheic dermatitis (5.36\%), urticaria $(3.98 \%)$, bacterial infection $(3.56 \%)$ (Table 1 $\&$ 2). Among the non-infective dermatoses, eczema $(27.7 \%)$, and acne $(5.98 \%)$ and seborrheic dermatitis $(5.36 \%)$ constituted top 3 most common dermatoses, whereas fungal infections $(11.2 \%)$, viral infections $(2.9 \%)$ and scabies $(2.67 \%)$ constituted top 3 infectious dermatoses. Maximum number of patients reported in the age group of $15-29(43.78 \%)$ years followed by 30 $44(24.45 \%)$ years. Males out numbered females in all age groups except those between 45-59 years, where females were predominantly involved.

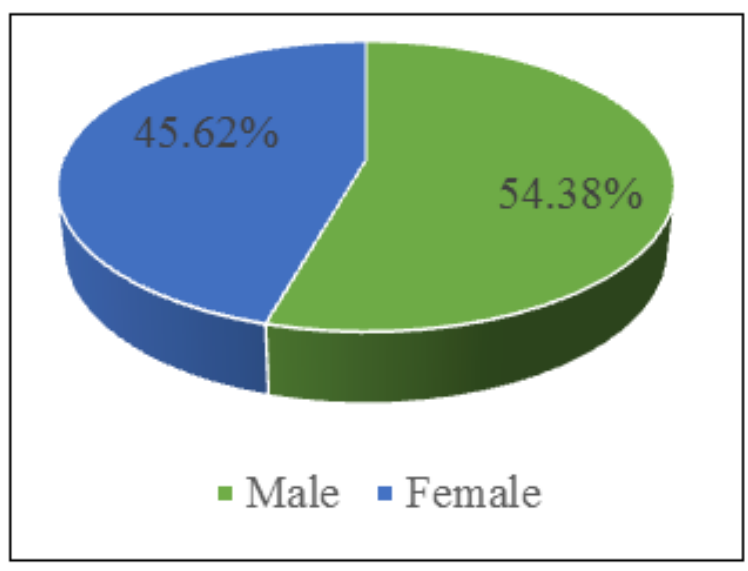

Fig-1: Sex distribution of patients 
Razu Ahmed \& Khorshed Alam Mondal., Saudi J Med Pharm Sci, September, 2020; 6(9): 610-615

\begin{tabular}{|c|c|c|}
\hline Disease & Number of patients & Percentage \\
\hline Eczema & 1721 & 27.7 \\
\hline Seborrheic dermatitis & 333 & 5.36 \\
\hline Acne & 371 & 5.98 \\
\hline Urticaria & 247 & 3.98 \\
\hline Photodermatitis & 33 & 0.53 \\
\hline Drug reaction & 41 & 0.66 \\
\hline Psoriasis & 69 & 1.11 \\
\hline Lichen planus & 43 & 0.7 \\
\hline SLE/DLE & 15 & 0.24 \\
\hline Melasma & 219 & 3.5 \\
\hline Vitiligo & 75 & 1.2 \\
\hline Benign skin growths \& skin tags & 177 & 2.85 \\
\hline Alopecia & 198 & 3.14 \\
\hline Erectile dysfunction \& premature ejaculation & 383 & 6.2 \\
\hline Total & 3940 & 63.5 \\
\hline
\end{tabular}

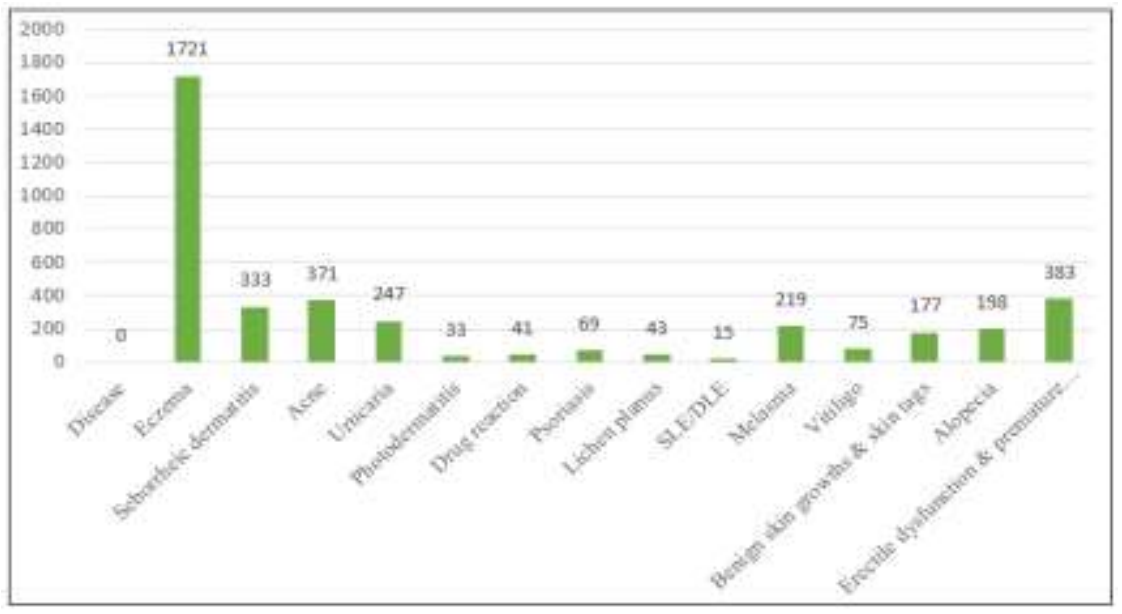

Fig-2: Incidence of non-infective dermatoses

Table-2: Incidence of infective dermatoses

\begin{tabular}{|l|l|l|l|}
\hline \multicolumn{2}{|l|}{ Disease } & Number of patients & \multicolumn{1}{|l|}{ Percentage } \\
\hline Fungal infections & 694 & 11.2 \\
\hline a. & Tinea capitis & 15 & 0.24 \\
\hline b. & Tinea corporis & 139 & 2.2 \\
\hline c. & Tinea cruris & 138 & 2.2 \\
\hline d. & Tinea pedis & 48 & 0.77 \\
\hline e. & Onychomycosis & 62 & 0.99 \\
\hline f. & Candidiasis & 131 & 2.11 \\
\hline g. & Pityriasis versicolor & 150 & 2.6 \\
\hline Bacterial infection & 221 & 3.56 \\
\hline a. & Furuncle/carbuncle & 94 & 1.5 \\
\hline b. & Impetigo & 42 & 0.67 \\
\hline c. & Gonorrhea & 42 & 0.16 \\
\hline d. & Syphilis & 10 & 0.25 \\
\hline e. & Nongonococcal urethritis & 16 & 0.89 \\
\hline Viral infection & 55 & 2.9 \\
\hline a. & Herpes simplex & 182 & 0.34 \\
\hline b. & Varicella & 21 & 0.42 \\
\hline c. & Herpes zoster & 26 & 0.77 \\
\hline d. & Warts & 48 & 1.4 \\
\hline Scabies & 87 & 2.67 \\
\hline Cutaneous tuberculosis & 166 & 0.03 \\
\hline Hansen's disease & 2 & 0.04 \\
\hline Total & 20.3 \\
\hline Miscellaneous (including both infective and non-infective dermatoses) & 1005 & 16.2 \\
\hline Total & 2263 & 36.5 \\
\hline
\end{tabular}


Razu Ahmed \& Khorshed Alam Mondal., Saudi J Med Pharm Sci, September, 2020; 6(9): 610-615

Table-3: Incidence in different age groups

\begin{tabular}{|l|l|l|l|l|l|l|}
\hline Age Group(Years) & \multicolumn{2}{|l|}{ Number Of Males (\%) } & \multicolumn{2}{l|}{ Number Of Females (\%) } & \multicolumn{2}{l|}{ Total Number Of Patients (\%) } \\
\hline$\leq 14$ & 474 & $(50.96)$ & 456 & $(49.03)$ & 930 & $(14.99)$ \\
\hline $15-29$ & 1434 & $(52.20)$ & 1282 & $(47.80)$ & 2716 & $(43.78)$ \\
\hline $30-44$ & 924 & $(60.90)$ & 593 & $(39.09)$ & 1517 & $(24.45)$ \\
\hline $45-59$ & 325 & $(48.65)$ & 343 & $(51.35)$ & 668 & $(10.76)$ \\
\hline$\geq 60$ & 216 & $(58.06)$ & 156 & $(41.94)$ & 372 & $(05.99)$ \\
\hline Total & 3373 & $(54.38)$ & 2830 & $(45.62)$ & 6203 & $(100)$ \\
\hline
\end{tabular}

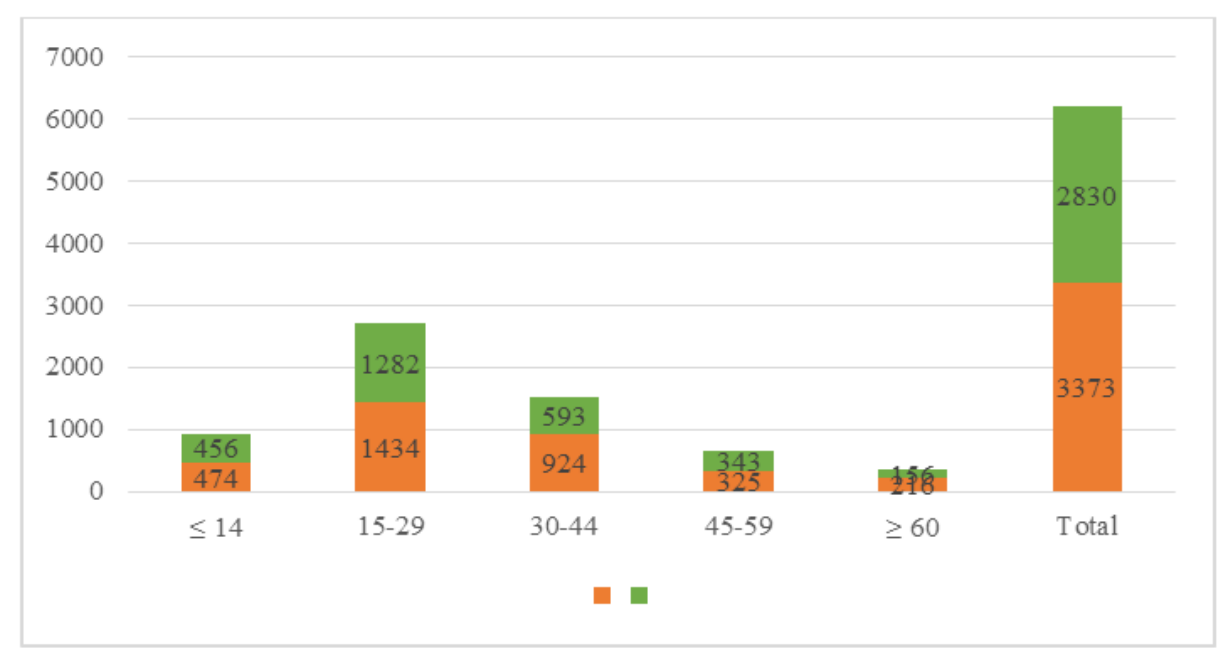

Fig-3: Incidence in different age groups patients

\section{DiscuSSION}

In this study non infectious patients were more than infectious patient. Most of the earlier studies have reported higher incidence of non-infective dermatoses $[12,14,16,30]$. Among the non infectious group eczema $(27.7 \%)$ is the most common followed by erectile dysfunction \& premature ejaculation (6.2\%), acne $(5.98 \%)$, seborrheic dermatitis (5.36\%). Emmanouil K S \& others [13]. in Mediteranean island found frequency of eczema comparative to our study. Moreover eczema topped the list of dermatoses in other studies [14-17]. In our study, acne was seen in $5.98 \%$ of the enrolled subjects. The frequency of acne in our study is somewhat similar to that in the past studies [14, 19, 30-34]. Maryum H et al., [27], Zamanian et al., [24] Tamizz Uddin et al., [28] and Agarwal et al., [29] have reported frequencies somewhat higher than our study. The frequency of urticaria $(3.98 \%)$ in the current study is somewhat similar to that in the past studies [31-34]. On the contrary, Maryum $\mathrm{H}$ et al., [27], Zamanian et al., [24] Tamizz Uddin et al., [28] and Agarwal et al., [29] have reported frequencies somewhat higher than our study. Out of all patients with papulosquamous disorder, psoriasis was seen in $1 \%$, while lichen planus in $0.7 \%$. Likewise the frequency of these disorders has also been reported to be around $1 \%$ or in the past studies [27, 28, 32-35]. However Ahmed et al., [34] have reported higher frequency as compared to the current study. On the contrary no comparable figures were quoted in the studies mentioned from Iran [24], Saudi Arabia [29]. Melasma (3.5\%) and vitiligo (1.2\%) were the most common pigmentary disorders in this study. Vinita G [26], Ahmed et al., [34] have reported a similar frequency for melasma. The frequency of vitiligo around $1 \%$ in the past studies [26, 31-33] is consistent with the current study. Hair disorders were recorded in 198 patients (3.14\%). Maryum H et al., [27] have reported the frequency of hair disorders to be $4 \%$, almost similar to our study, whereas Ahmed et al., [34] have reported the frequency of hair disorders to be $8 \%$, almost twice that recorded in our study. In the current study, infections had a frequency of $20.2 \%$. the frequency of infections was reported to be more or less equivalent in the study by Maryum $\mathrm{H}$ et al., [27] and Tamizz Uddin et al., [28] On the other hand past studies from Karachi [31, 34], Lahore [32], Bahawalpur [33], reported a higher a frequency as compared to the current study. On the contrary Devi and Zamzachin [14] and some other studies [18, 26] have reported more higher incidence. This difference could be explained by a differenc in setting and design of the studies. Among the infectious group fungal infection is the commonest $(11.2 \%)$ form of dermatological presentation followed by viral infections (2.9\%), scabies $(2.67 \%)$ and pyoderma $(2.17 \%)$. Similar findings were found in studies conducted by Sk Sarker and AKMS Islam [18], Karanti BK [19], Sharma et al., [29] and Vinita G [26]. This can be attributed to the climatic differences between different geographical areas. Similarly in our study, maximum cases of fungal infections were reported during rainy season, heat and humidity being the important factors contributing to their higher incidence. Very low incidence of Hansen's disease and cutaneous tuberculosis, similar to most other studies 
$[14,18,30]$, can be attributed to the fact that these patients mainly attend either government hospitals or leprosy centers and DOT centers where MDT are distributed free of cost. In our study age of the patients enrolled varied from birth to 90 years. Age groups between $15-29$ years $(43.78 \%)$ were reported to have maximum incidence followed by $30-44$ years $(24.45 \%)$. Age group of 11-30 years was reported to have maximum incidence in a study from Allahabad [14], while other studies reported maximum incidence in age groups of 20-30 and 30-40 years [21, 22]. A study [26], from Haryana showed maximum incidence in the age group of 30-44 years closely followed by 15-29 years. Males outnumbered females in our study $(\mathrm{M} / \mathrm{F}=54.38 / 45.62)$. Some studies have reported male preponderance [17], while other studies have reported female preponderance $[16,25]$. Interestingly we found $383(6.2 \%)$ patients of erectile dysfunction \& premature ejaculation in our dermatology \& Venereology OPD. In our study we found maximum patients from o to 14 years' age group. So age may be a vital factor in the treatment in several infectious as well as non-infectious skin diseases in this region.

\section{CONCLUSION}

We can conclude that young age group is the most vulnerable group for skin related diseases in Bangladesh. Our study found a higher prevalence of non-infective dermatoses than infective dermatoses. Eczema and fungal infections formed the largest group in their respective categories. Since males and young adults were found to be mostly affected and eczema and fungal infections found to be the most common diseases, nature of occupation, living conditions, lack of awareness all contribute to an increasing burden of skin $\&$ venereal diseases in the society. Government and policy maker should give more attention to this group for being a healthy society with free of skin diseases. Role of public awareness regarding personal and community hygiene and timely reporting of skin \& venereal diseases is of great importance for reducing disease burden and improved quality of life.

\section{REFERENCES}

1. Rook, A., Savin, J. A., \& Wilkinson, D. S. (1987). The prevalence, incidence and ecology of diseases of skin, In: Rook, A., Wilkinson, D. S., Ebling, F. J., Champion, R. H., \& Burton, J. L., editors, Text book of Dermatology. Oxford University Press: Mumbai. 39-53.

2. Parthasaradhi, A., \& Al Gufai, A. F. (1998). The pattern of skin diseases in Hail region, Saudi Arabia. Annals of Saudi medicine, 18(6), 558-561.

3. Atraide, D. D., Akpa, M. R., \& George, I. O. (2011). The pattern of skin disorders in a Nigerian tertiary hospital. Journal of Public health and epidemiology, 3(4), 177-181.
4. Devi, T. B., \& Zamzachin, G. (2006). Pattern of skin diseases in Imphal. Indian journal of Dermatology, 51(2), 149.

5. Symvoulakis, E. K., Krasagakis, K., Komninos, I. D., Kastrinakis, I., Lyronis, I., Philalithis, A., \& Tosca, A. D. (2006). Primary care and pattern of skin diseases in a Mediterranean island. $B M C$ Family Practice, 7(1), 6.

6. Grover, S., Ranyal, R. K., \& Bedi, M. K. (2008). A cross section of skin diseases in rural Allahabad. Indian journal of dermatology, 53(4), 179-181.

7. Jain, S., Barambhe, M. S., Jain, J., Jajoo, U. N., \& Pandey, N. (2016). Prevalence of skin diseases in rural Central India: A community-based, crosssectional, observational study. Journal of Mahatma Gandhi Institute of Medical Sciences, 21(2), 111-15.

8. Kar, C., Das, S., \& Roy, A. K. (2014). Pattern of skin diseases in a tertiary institution in Kolkata. Indian journal of dermatology, 59(2), 209.

9. Chua- Ty, G., Goh, C. L., \& Koh, S. L. (1992). Pattern of skin diseases at the National Skin Centre (Singapore) from 1989-1990. International journal of dermatology, 31(8), 555-559.

10. El- Khateeb, E. A., Imam, A. A., \& Sallam, M. A. (2011). Pattern of skin diseases in Cairo, Egypt. International journal of dermatology, 50(7), 844-853.

11. Onayemi, O., Isezuo, S. A., \& Njoku, C. H. (2005). Prevalence of different skin conditions in an outpatients' setting in north- western Nigeria. International journal of dermatology, 44(1), 7-11.

12. Rao, G. S., \& Kumar, S. S. (2003). Pattern of skin diseases in an Indian village. Indian journal of medical sciences, 57(3), 108-110.

13. Symvoulakis, E. K., Krasagakis, K., Komninos, I. D., Kastrinakis, I., Lyronis, I., Philalithis, A., \& Tosca, A. D. (2006). Primary care and pattern of skin diseases in a Mediterranean island. $B M C$ Family Practice, 7(1), 6.

14. Devi, T. B., \& Zamzachin, G. (2006). Pattern of skin diseases in Imphal. Indian journal of Dermatology, 51(2), 149-150.

15. Metha, T. K. (1962). Pattern of skin diseases in India. Indian J Dermatol Venerol Leprol. 28:134139.

16. Gangadharan, C., Joseph, A., \& Sarojini, P. A. (1976). Pattern of Skin Diseases in Kerala. Indian journal of dermatology, venereology and leprology, 42(2), 49.

17. Dayal, S. G., \& Gupta, G. D. (1977). A cross section of skin diseases in Bundelkhand region, UP. Indian Journal of Dermatology, Venereology, and Leprology, 43(5), 258.

18. Sarkar, S. K., Islam, A. K. M. S., Sen, K. G., \& Ahmed, A. R. S. (2010). Pattern of skin diseases 
in patients attending OPD of dermatology department at Faridpur Medical College Hospital, Bangladesh. Faridpur Medical College Journal, 5(1), 14-16.

19. Bhalla, K. (1984). Pattern of skin diseases in a semi-urban community of Delhi. Indian Journal of Dermatology, Venereology, and Leprology, 50(5), 213-214.

20. Sharma, N. L., \& Sharma, R. C. (1990). Prevalence of dermatologic diseases in school children of a high altitude tribunal area of Himachal Pradesh. Indian Journal of Dermatology, Venereology, and Leprology, 56(5), 375-376.

21. Joel, J. J., Jose, N., \& Shastry, C. S. (2013). Patterns of skin disease and prescribing trends in rural India. Sch Acad J Pharm, 2(4), 304-09.

22. Mishra, N., Srivastava, N., Gahalaut, P., \& Rastogi, M. K. (2016). Pattern of dermatological disorders in a private skin clinic of Rohilkhand region in India. Journal of Pakistan Association of Dermatology, 24(2), 138-142.

23. Grover, S., Ranyal, R. K., \& Bedi, M. K. (2008). A cross section of skin diseases in rural Allahabad. Indian journal of dermatology, 53(4), 179.

24. Zamanian, A., \& Mahjub, H. (2005). Prevalence of skin diseases in Hamedan, Iran in 2002. Indian Journal of Dermatology, 50(4), 208-211.

25. Kuruvilla, M., Sridhar, K. S., Kumar, P., \& Rao, G. (2000). Pattern of skin diseases in Bantwal
Taluq, Dakshina Kannada. Indian Journal of Dermatology, Venereology, and Leprology, 66(5), 247-248.

26. Gupta, V. (2015). Pattern of skin diseases in rural India: A hospital based study. Int J Sci Study, 3(1), 44-7.

27. Maryum, H., Alam, M. Z., \& Ahmed, I. (2016). Pattern of skin diseases in a tertiary care private hospital, Karachi. Journal of Pakistan Association of Dermatology, 24(4), 292-297.

28. Tameez-Ud-Din, B. A., Bangash, F. A., \& Abbas, H. (2010). Burden of skin diseases at a tertiary care hospital. J Rawalpindi Med Coll, 14, 90-2.

29. Agarwal, P. K. (1997). Pattern of skin diseases in Al-Jouf region. Annals of Saudi medicine, 17(1), 112-114.

30. Das, K. K. (2003). Pattern of dermatological diseases in Gauhati Medical College and Hospital Guwahati. Indian journal of dermatology, venereology and leprology, 69(1), 16.

31. Haroon, T. S. (1985). Pattern of skin diseases in Karachi. J Pak Med Assoc, 35, 73-8.

32. Shabbir, G. (1961). Dermatoses prevalent in Lahore. The Medicus, 22, 33-42.

33. Qamar, A. G., \& Malik, R. A. (2000). Skin diseases in Bahawalpur. J Pak Assoc Dermatol, 10, 3-8.1

34. Ahmed, I., Ansari, M., \& Malick, K. (2017). An audit of dermatoses at Baqai institute of skin diseases, Karachi. Journal of Pakistan Association of Dermatology, 13(3), 117-122. 